\title{
ULAMA DAN NEGARA SANTRI
}

\author{
Ahmad Najib Burhani
}

\begin{abstract}
Abstrak
Dengan kemenangan Joko Widodo - Ma'ruf Amin dalam Pemilihan Presiden 2019, ulama kembali menempati posisi penting dalam pemerintahan Republika Indonesia. Pertanyaannya, apakah dengan terpilihnya Ma'ruf Amin sebagai Wakil Presiden itu akan mendinginkan perpolitikan nasional yang selama ini sering terbelah antara kubu nasionalis dan Islamis? Apakah tampilnya Ma'ruf Amin, yang merupakan mantan rois 'am NU, sebagai bagian dari ashabul qoror (penentu kebijakan) akan bisa menghilangkan berbagai kebijakan yang kurang berpihak dari pemerintah terhadap minoritas atau justru melahirkan sektarianisme baru? Dua pertanyaan inilah yang ingin diangkat oleh artikel ini.
\end{abstract}

Kata kunci : Ulama, Islam, Santri, Nasionalis 


\section{Pendahuluan}

Menjelang Ramadan kemarin (3/5), ratusan ulama berkumpul di Jakarta untuk mengadakan kegiatan yang diberi nama Multaqo Ulama. Selain sebagai upaya menyambut Ramadan, pertemuan yang diprakarsai oleh KH Maimun Zubair itu dimaksudkan sebagai respon terhadap kondisi nasional pasca pemilu. Dengan mengambil tema "Untuk Kemaslahatan Bangsa”, pertemuan itu, di antaranya, membahas tentang ukhuwah (persaudaraan), ishlah (rekonsiliasi), muwathonah (kebangsaan).

Sebagian orang tentu melihat kegiatan itu sebagai tanggapan terhadap Ijtima' Ulama III yang diadakan di Bogor (1/5). Kegiatan yang diadakan oleh pengurus GNPF (Gerakan Nasional Pengawal Fatwa) dan para politisi pendukung Prabowo Subianto-Sandiaga Uno, seperti Yusuf Martak, Slamet Maarif, dan Bachtiar Nasir, itu secara khusus mempersoalkan pelaksanaan dan hasil Pemilu yang dilaksanakan pada 17 April yang lalu.

Di luar persoalan yang dibahas, dua kegiatan itu mengindikasikan bahkan peran ulama dalam perpolitikan nasional menjadi semakin penting belakangan ini. Mengingat tugas ulama atau kyai itu di antaranya adalah, meminjam istilah Clifford Geertz (1960), sebagai value holder (pemegang nilai-nilai) dan cultural broker (mediator atau jembatan budaya), maka tampilnya ulama dalam kancah perpolitikan nasional, termasuk sebagai wakil presiden, tentu menjadi sesuatu yang mestinya bernilai positif.

Persoalannya, apa yang dilakukan oleh sebagian dari mereka yang menyebut dirinya ulama itu seperti tak berbeda dari apa yang dilakukan para politisi. Alih-alih memerankan diri sebagai "pemegang nilai", sebagian dari ulama itu justru tampak lebih buruk dari politisi. Ketika para politisi sudah mulai merenggangkan otot-otot kemarahannya pasca pemilu dan sebagian bahkan sudah mulai menjajagi koalisi dengan mereka yang menjadi lawannya saat pemilu, beberapa ulama tetap keras kepala, masih kaku, fanatik, dan tak hentihentinya melanjutkan permusuhan yang terjadi pada saat pemilu. Lantas, seperti apa kondisi kebangsaan kita mendatang jika para ulamanya menjadi pihak yang terus-menerus bertengkar dan berpolitik? 


\section{Varian Santri}

Pembicaraan tentang ulama itu tentu tak bisa dipisahkan dari santri sebagai kelompok masyarakat yang menopang lahirnya ulama. Dan munculnya berbagai macam ulama di panggung nasional saat ini juga terkait erat dengan berbagai varian santri yang ada di Indonesia. Ketika Clifford Geertz menggunakan kata santri dalam bukunya The Religion of Java (1964), maka yang dimaksud dengan istilah itu hanya mengacu kepada dua kelompok, "santri kolot" dan "santri moderen". Yang pertama direpresentasikan oleh kelompok tradisionalis, terutama NU (Nahdlatul Ulama), sedangkan yang kedua diwakili oleh Muhammadiyah. Istilah santri sendiri umumnya didefinisikan sebagai mereka yang memiliki kepedulian kuat kepada doktrin dan praktik keagamaan.

Lima puluh tahun setelah Geertz mempopulerkan trikotomi santri, priyayi, dan abangan di kalangan akademisi internasional, banyak perubahan terjadi wilayah penelitiannya, Modjokuto (Pare, Kediri), dan juga di Indonesia secara umum. Konsep santri, misalnya, tak bisa dibatasi dalam dua kategori di atas. Muncul berbagai varian baru seperti santri neo-modernis, neo-revivalis, radikal, dan liberal.

Santri neo-modernis mengacu kepada para pengikut almarhum Nurcholish Madjid dan para alumni UIN / IAIN yang sebagian dari mereka tak pernah mengenyam pendidikan pesantren. Santri neo-revivalis mengacu kepada para pembelajar agama melalui halaqoh-halaqoh dan gerakan tarbiyah yang banyak bertebaran di kampus seperti ITB, UGM, dan IPB. Selain individu-individu yang mentransformasikan diri menjadi santri, sebagian dari santri neo-modernis dan neo-revivalis merupakan konvergensi dan, sebagian lagi, divergensi dari dua jenis santri yang lama.

Varian santri radikal adalah mereka yang biasanya tergabung dalam organisasi semisal JI (Jemaah Islamiyah) dan ex-HTI (Hizbut Tahrir Indonesia). Sementara mereka yang tergabung dalam JIL (Jaringan Islam Liberal) sering disebut sebagai santri liberal. Bahkan, kini ada varian yang lebih baru lagi, meski hanya muncul dalam pemilu kemarin, yaitu santri post-Islamisme. Istilah ini dipakai oleh presiden PKS, Sohibul Iman, untuk mendefinisikan kesantrian dari Sandiaga Uno.

Berbagai varian santri itulah yang kemudian melahirkan berbagai varian ulama yang belakangan ini muncul di panggung politik nasional. Karena proses pendidikan masing-masing varian itu berbeda, standar untuk mengukur 
kesantrian dan keulamaan juga ada perbedaan. Kadang terjadi ketegangan di antara mereka dalam menerjemahkan ajaran agama dan melihat hubungan agama dengan politik. Kontestasi antar-santri itu misalnya bisa dilihat dari upaya penyempitan definisi santri yang hanya mengacu kepada santri tradisional dan mereka yang lulusan pesantren. Ini bisa dilihat, misalnya, dengan fenomena Hari Santri 22 Oktober yang sepertinya hanya mengacu kepada NU. Ormas Islam lain atau varian santri lain seperti belum ada perasaan memiliki terhadap keberadaan Hari Santri tersebut.

\section{Santri di Pusaran Politik, "secular state"}

Istilah "negara santri" (santri state) memang belum terkenal luas, baik di lingkungan akademik maupun dalam perbincangan para politisi. Istilah ini mulai dipakai, di antaranya, oleh para peneliti di RSIS NTU Singapura ketika melakukan riset tentang fenomena politik-keagamaan di Indonesia saat ini. Tentu saja istilah ini mengindikasikan sebuah sistem pemerintahan yang berbeda dari theocratic state, secular state, dan sistem lain yang selama ini dikenal.

Meski istilah itu tak dikenal dan bahkan belum terbangun secara teoritis, namun ia menjadi relevan untuk membaca pemerintahan Joko Widodo pada periode kedua yang berpasangan dengan KH Ma'ruf Amin. Apalagi dengan melihat semakin sentralnya peran santri dan ulama dalam negara, pemerintahan, dan perpolitikan nasional sekarang.

Fenomena seorang santri menjadi pemimpin tinggi negara tentu bukan kali ini saja. Sebelumnya, Abdurrahman Wahid atau Gus Dur merupakan contoh bagaimana seorang santri menduduki kekuasaan tertinggi negara. Bukan sekadar menjadi wakil presiden, tapi menjadi presiden Republik Indonesia. Perbedaannya, Ma'ruf Amin membawa gerbong NU sejak masa kampanye dan berjuang bersama-sama memenangkan Jokowi. Sementara sebagian dari ulama non-NU memilih berada di barisan yang berseberangan dan bahkan, meski Pemilu telah usai, sebagian belum surut penentangannya terhadap Ma'ruf Amin serta pemerintahan Jokowi.

Idealnya, sebuah "negara santri" akan menjadi tempat yang nyaman bagi berseminya nilai-nilai keagamaan yang luhur. Namun sebelum pertentangan para santri dan ulama dari berbagai varian itu usai, sepertinya kita masih harus menunggu terwujudnya tatanan masyarakat yang harmonis. Ketika 
Ma'ruf Amin dan NU berhasil menjadi bagian dari ashabul qoror (pemangku kekuasaan) di pemerintahan Jokowi, banyak yang berharap ßakan munculnya hubungan antar-agama yang semakin baik, terutama bila melihat track-record dari NU. Namun sepertinya, pemerintah perlu segera menyelesaikan persoalan intra-agama atau perseteruan antara umat Islam itu sendiri terlebih dahulu. Ada sebagian dari umat Islam yang agaknya belum rela dan ketakutan dengan naiknya Ma'ruf Amin dan NU di pusaran kekuasaan sebagai ashabul qoror. 


\section{Daftar pustaka}

Albertazzi, Daniele and Duncan McDonnell, "Introduction: The Sceptre and the Spectre" dalam Albertazzi, Daniele and Duncan McDonnell (ed.), Twenty-First Century Populism: The Spectre of Western European Democracy (London: Palgrave MacMillan, 2008) hal. 1-11.

Basya, M Hilali, Muhammadiyah Scholars and Democratic Transition: Response on Radical Islam Movements in Post-New Order Indonesia (Jerman dan UK: VDM, 2011).

Basya, M Hilali, "Muhammadiyah Scholars and Democratic Transition in Post-New Order Indonesia: The Critical Response of Muhammadiyah Scholars to Radical Islamist Movements" dalam Kultur the Indonesian Journal for Muslim Cultures, Vol. 5, No. 1 (2010).

Basya, M Hilali, Islam, Secularity and the State in Post-New Order Indonesia: Tensions between Neo-Modernist and Revivalist Leaderships in the Muhammadiyah, 1998-2005 (Disertasi di University of Leeds, Inggris; dipublikasi secara online di etheses.whiterose.ac.uk).

Bayat, Asef, Making Islam Democratic: Social Movements and the Post-Islamist Turn (California: Stanford University Press, 2007).

Hadiz, Vedi R, "ANew Islamic Populism and the Contradictions of Development" dalam Journal of Contemporary Asia, Vol. 44, No. 1 (2014), hal. 125-143.

Hadiz, Vedi R, Islamic Populism in Indonesia and the Middle East (Cambridge: Cambridge University Press, 2016).

Mietzner, Marcus, "Fighting Illiberalism with Illiberalism: Islamist Populism and Democratic Deconsolidation in Indonesia" dalam Pacific Affairs, Vol. 91, No. 2 (2018), hal. 261-282.

Mudde, Cas and Cristobal Rovira Kaltwasser (eds.), Populism in Europe and the Americas: Threat or Corrective for Democracy (Cambridge: Cambridge University Press, 2012).

Mujani, Saiful and William Liddle, "Muslim Indonesia's Secular Democracy" dalam Asian Survey, Vol. 49, No. 4 (2009), hal. 575-590. 
Mujani, Saiful, Religious Democrats: Democratic Culture and Muslim Political Participation in Post-Suharto Indonesia (disertasi di The Ohio State University, 2003).

Putnam, Robert D, Democracies in Flux: The Evolution of Social Capital in Contemporary Society (New York: Oxford University Press, 2002).

Wuthnow, Robert, "Mobilizing Civic Engagement: The Changing Impact of Religious Involvement" dalam Theda Skocpol and Morris P. Fiorina (ed.) Civic Engagement in American Democracy (Washington D.C.: Brooking Institution Press, 1999).

Burhani, Ahmad Najib. "Geertz's Trichotomy of Abangan, Santri, and Priyayi: Controversy and Continuity." Journal of Indonesian Islam. 11.2 (2017): $329-350$.

Geertz, Clifford. The Religion of Java. Glencoe, Ill: Free Press of Glencoe, 1964.

Geertz, Clifford. "The Javanese Kijaji: the Changing Role of a Cultural Broker.” Comparative Studies in Society and History. 2.2 (1960): 228-249. 